\title{
Parvovirose e anemia acentuada em paciente imunocompetente
}

Primeira submissão em 06/05/11 Última submissão em 06/05/11 Aceito para publicação em 29/12/11 Publicado em 20/04/12

\section{Parvovirus and severe anemia in an immunocompetent patient}

Juliana Annete Damasceno'; Hebert Praxedes²; Monica Kopschitz Praxedes³; Andrea Rodrigues Cordovil Pires ${ }^{4}$; Adelmo Henrique Dalmas Gabriel${ }^{5}$; Carolina Donatti6; Roberta Moreira Damião ${ }^{7}$

\section{unitermos \\ Parvovírus \\ Anemia}

Imunocompetente

\section{resumo}

Paciente de 16 anos, sexo masculino, com vírus da imunodeficiência humana (HIV) negativo e sem doença hematológica prévia, desenvolveu anemia acentuada devido à infecção por parvovírus B19. A doença apresentou evolução bifásica, com acalmia clínica e retorno dos sintomas após 15 dias. Ao exame físico, apresentava-se descorado e febril, sem adeno e organomegalias, com sinais de insuficiência cardíaca. O aspirado de medula óssea mostrava megaloblastos com nucléolos aberrantes e, na histologia, foram observadas células gigantes com nucleolação aberrante e presença do corpúsculo de inclusão nuclear típico da parvovirose. $O$ exame de imuno-histoquímica mostrou positividade para anticorpo específico para parvovírus. A sorologia comprovou a infecção.

\section{abstract}

A 16-year-old human immunodeficiency virus (HIV) negative male patient without hematological disease developed acute anemia due to parvovirus B19 infection. The disease showed a biphasic evolution: clinical remission and return of symptoms after 15 days. Physical examination revealed paleness and fever, neither adeno nor organomegalies, and signs of heart failure. The bone marrow aspiration showed megaloblasts with aberrant nucleoli. As far as histology is concerned, giant cells with aberrant nucleoli and the presence of intranuclear inclusions typical of Parvoviruses were observed. Immunohistochemistry revealed positivity for specific Parvovirus antibody. Serology confirmed parvovirus B19 infection. key words

\section{Parvovirus}

Anemia

Immunocompetent

\footnotetext{
1. Médica; mestra em Saúde da Criança e do Adolescente.

2. Live-docente da Universidade Federal do Rio de Janeiro (UFR)); professor emérito da Universidade Federal Fluminense (UFF).

3. Doutora em Patologia; chefe do Serviço de Hematologia do Hospital Universitário Antônio Pedro (HUAP).

4. Mestra em Patologia; patologista do HUAP.

5. Mestre em Biologia Molecular e Celular; professor de Hematologia do HUAP.

6. Craduanda em Medicina.

7. Médica.
} 


\section{Introdução}

O parvovírus B19, também denominado eritrovírus B19, é um vírus DNA que pertence ao gênero dos Erythrovirus e é o único membro da família dos Parvoviridae que infecta o homem ${ }^{(6,10)}$.

O tropismo do parvovírus leva à infecção dos precursores eritroides determinando o bloqueio transitório da eritropoese, podendo causar várias síndromes clínicas, entre elas, eritema infeccioso, hidropsia fetal não imune, crise aplástica e anemia crônica dos indivíduos imunossuprimidos $^{(1)}$.

Outras alterações na linhagem hematológica, com graus variados de neutropenia e trombocitopenia, também têm sido associadas ao parvovírus $\mathrm{B} 19^{(9)}$.

\section{Relato do caso}

Relatamos o caso de um estudante de 16 anos, sexo masculino, com vírus da imunodeficiência humana (HIV) negativo e sem doença hematológica de base, que desenvolveu anemia acentuada devido à infecção por parvovírus B19. O quadro clínico inicial foi caracterizado por febre, icterícia e queda do estado geral, com o primeiro hemograma mostrando série vermelha, reticulócitos, leucócitos e plaquetas normais. A doença apresentou evolução bifásica, com acalmia clínica e retorno dos sintomas após 15 dias. O paciente teve febre, exantema, cansaço e palidez cutâneo-mucosa, além da queda da hemoglobina $(\mathrm{Hb})$ de $12,5 \mathrm{~g} / \mathrm{dl}$ para $7 \mathrm{~g} / \mathrm{dl}$, em quatro semanas, e reticulocitopenia acentuada. Ao exame físico, apresentava-se descorado e febril, sem adeno e organomegalias, com sinais de insuficiência cardíaca, tendo sido internado para transfusões de concentrado de hemácias e infusão de imunoglobulina (lg) venosa devido à suspeita de parvovirose. Houve desaparecimento da febre e da adinamia e retorno do hemograma aos níveis normais em poucas semanas. $\mathrm{O}$ aspirado de medula óssea mostrava frequentes megaloblastos com nucléolos aberrantes e, na histologia, foram observadas células gigantes com nucleolação aberrante e presença do corpúsculo de inclusão nuclear típico da parvovirose. O exame de imuno-histoquímica (IHQ) mostrou positividade para anticorpo específico para parvovírus em numerosas células eritroides, além de células granulocíticas. A sorologia comprovou a infecção por parvovírus B19 (Figuras 1, 2, 3 e 4).

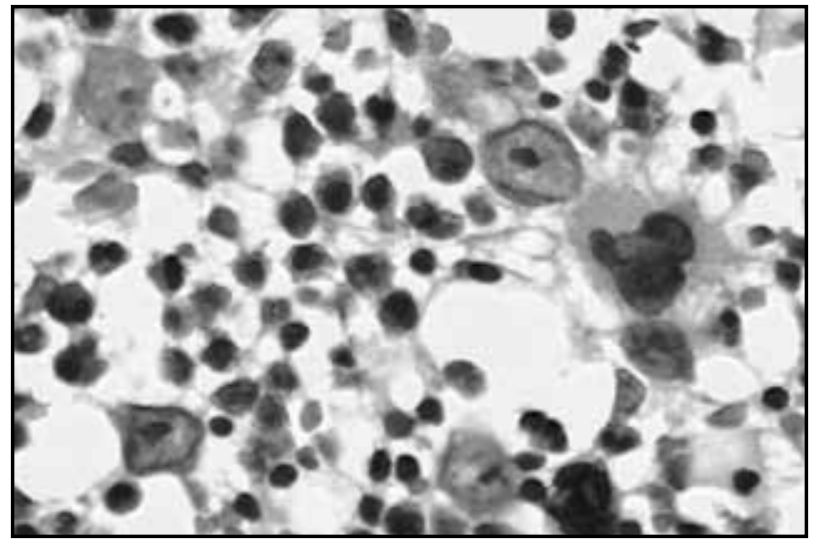

Figura 1 - Biópsia de medula óssea exibindo pró-megalobastos volumosos e atípicos (HE, 40x)

$H E$ : hematoxilina e eosina

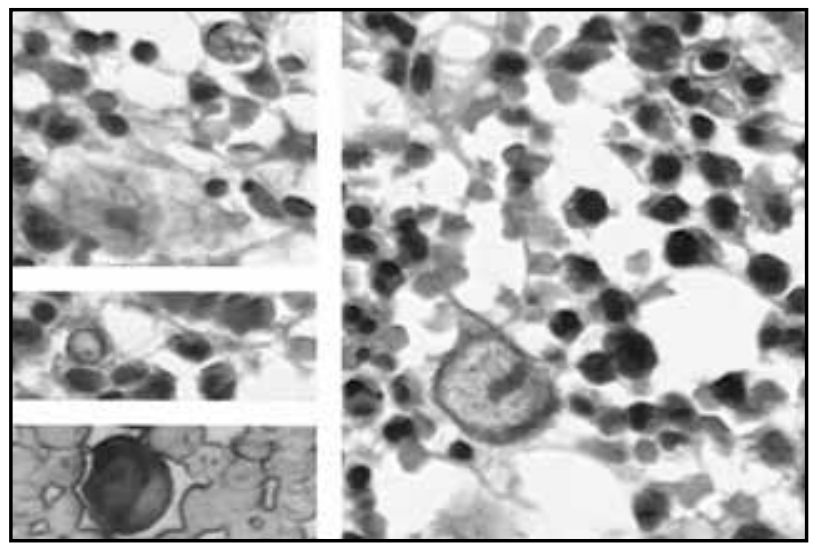

Figura 2 - Biópsia de medula óssea e mielograma exibindo pró-megalobastos volumosos e atípicos e eritroblastos com inclusões nucleares (HE e Giemsa, 40x) HE: hematoxilina e eosina.

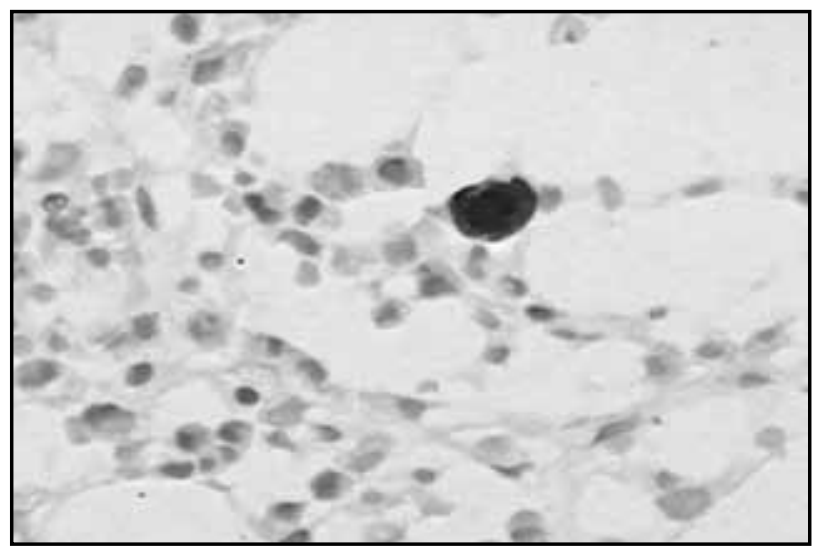

Figura 3 - Biópsia de medula óssea exibindo eritroblasto com imunopositividade com o anticorpo antiparvovírus (IHQ, 40x)

IHQ: imuno-histoquímica.

\section{Discussão}

A infecção por parvovírus B19 ocorre mais comumente na infância e a imunidade perdura por toda a vida. Nas crianças, o parvovírus é responsável pelo aparecimento do 


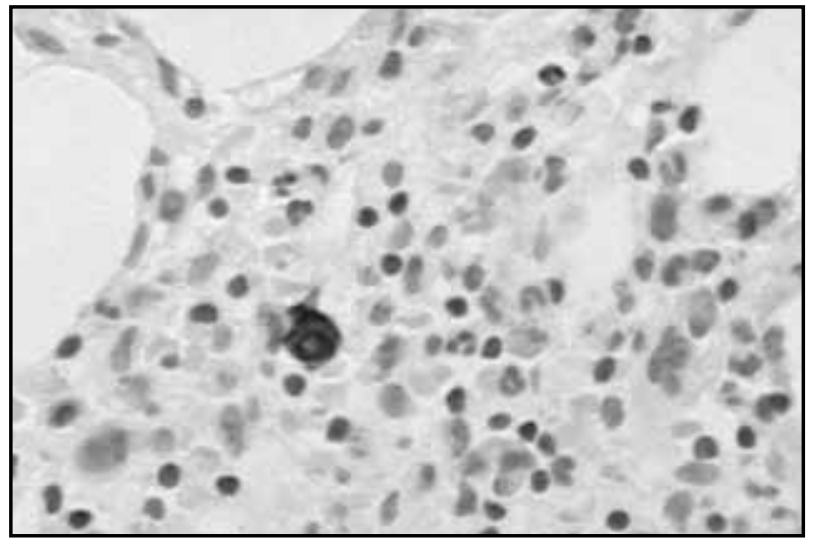

Figura 4 - Biópsia de medula óssea exibindo eritroblasto com imunopositividade com 0 anticorpo antiparvovírus (IHQ, 40X)

IHQ: imuno-histoquímica

eritema infeccioso, ou quinta doença, cursando com febre baixa e rash cutâneo ${ }^{(10)}$.

Nos indivíduos adultos imunocompetentes, a infecção pode ser assintomática ou oligossintomática, com quadro febril não característico ${ }^{(10)}$. Nos pacientes sintomáticos, não há sintomas hematológicos, ocorrendo doença autolimitada com febre, cefaleia, artralgias, exantema, coriza, náuseas e diarreias ocasionais ${ }^{(10)}$. Os indivíduos saudáveis apresentam hemácias que circulam por 120 dias. Dessa forma, a infecção se cura espontaneamente antes que os sintomas hematológicos ocorram ${ }^{(8)}$.

Nos indivíduos com anemia hemolítica, é comum a ocorrência da crise aplástica transitória. Tipicamente, esses pacientes apresentam pródromo, seguido de anemia, com queda da $\mathrm{Hb}$ abaixo de $5 \mathrm{~g} / \mathrm{dl}$. A recuperação é espontânea e a recorrência não ocorre( ${ }^{(7)}$.

A crise aplástica transitória também pode ser vista em imunocompetentes sob determinadas condições, como malária e deficiência acentuada de ferro ${ }^{(7)}$.
Em indivíduos imunocomprometidos, mais comumente com a síndrome da imunodeficiência adquirida (AIDS), pode ocorrer infecção crônica caracterizada por queda dos precursores eritroides na medula óssea, reticulocitopenia e anemia normocítica/normocrômica ${ }^{(5,7,10)}$. Outras condições clínicas têm sido relacionadas com quadros de anemia persistente causada pelo parvovírus, como neoplasias hematológicas, entre elas, leucemias linfoides e mieloides agudas, linfomas, leucemias mieloides crônicas e síndromes mielodisplásicas; pacientes submetidos à quimioterapia com uso de anticorpos monoclonais, como anti-CD20/rituximabe, e transplante de medula óssea (TMO); transplantados de órgãos e, em alguns casos, de portadores de tumores sólidos, como astrocitoma e tumor de Wilms ${ }^{(4,7)}$.

Nas leucemias agudas, especialmente nas crianças, têm sido descritas infecções pelo parvovírus, simulando recidiva da doença ou citopenia relacionada com a quimioterapia. Têm sido relatados também casos de infecções por parvovírus, precedendo ou ocorrendo em associação a leucemias agudas e soroprevalência aumentada em pacientes adultos que recebem múltiplos ciclos de quimioterapia ${ }^{(4)}$.

A infecção por parvovírus pode provocar o aparecimento de pró-eritroblastos gigantes na citologia da medula óssea e inclusões nucleares nos eritroblastos, mais bem observadas no exame histológico e comprovadas pela IHQ ${ }^{(2)}$. Os pró-eritroblastos gigantes são vistos com muita frequência nas infecções pelo parvovírus B19, porém não estão presentes em $100 \%$ dos $\operatorname{casos}^{(2)}$.

O caso relatado tem como aspecto de interesse especial o desenvolvimento de um quadro de anemia acentuada, de instalação rápida e com necessidade transfusional, em um paciente jovem e imunocompetente com parvovirose, no qual seria esperada uma forma de infecção oligossintomática e sem repercussões hematológicas graves, mesmo que transitórias.

\section{Referências}

1. ANADYR, L. M. et al. Study of chronic hemolytic anemia patients in Rio de Janeiro: prevalence of anti-Human parvovirus B19 antibodies and the development of transient aplastic crises. Rev Inst Med Trop São Paulo, v. 44, n. 4, p. 188-90, 2002.

2. BROWN, K. E.; YOUNG, N. S. Parvoviruses and bone marrow failure. Stem Cell, v. 14, n. 2, p. 151-63, 1996.

3. CORCORAN, A.; DAYLE, S. Advances in the biology, diagnosis and host-pathogen interaction of parvovirus B19. J Med Microbiol, v. 53, n. Pt6, p. 459-75, 2004.
4. HARTMANN, J. T. et al. Progressive bicytopenia due to persistent parvovirus B19 infection after immunochemoterapy with fludarabine/ ciclophosphamide and rituximab for relapsed $\mathrm{B}$ cell lymphoma. Hematol, v. 91, n. 10, p. 135-6, 2006.

5. HEEGAARD, E. D. et al. Parvovirus B19 infection in patients with chronic anaemia. Hematol, v. 82, p. 402-5, 1997.

6. QUIAN, X. H. et al. Aplastic anemia associated with parvovirus B19 infection. Arch Dis Child, v. 87, p. 436-7, 2002. 
7. SABELLA, C.; GOLDFARB, J. Parvovirus B19 infection. Am Fam Physician, v. 60, p. 1455-60, 1990.

8. SETUBAL, S. et al. Aplastic crises caused by parvovirus B19 in an adult patient with sickle-cell disease. Rev Soc Bras Med Trop, v. 33, n. 5, p. 477-81, 2000.

9. YONG, N. S.; ABKOWITZ, J. L.; LUIZZATTO, L. New insights into pathophysiology of acquired cytopenias.
Hematology Am Soc Hematol Educ Program, p. 18-38, 2000.

10. ZIVAEVAN, M.; RASOULI, M.; ALBORZI, A. The seroprevalence of parvovirus B19 infection among to-be-married girls, pregnant women and their neonates in Shiraz, Iran. Jpn J Infect Dis, v. 58, p. 95-7, 2005. 